\title{
15
}

\section{Benchmarking of Tandberg Data against EFQM's (The European Foundation for Quality Management) Assessment Model}

\section{Colin Jeneson*}

* Corporate Manager, Strategic Quality \& Partnerships, Tandberg Data A/S, Post Box 134 Kjelsaas, 0411 Oslo, Norway

The following article describes Tandberg Data's limited experience of Benchmarking and is related to Total Quality Management criteria. But first, it is necessary to put the activity into perspective by reflecting on some of the issues facing the company I represent and the business world at large.

\subsection{GENERAL TRENDS IN EUROPE}

In today's turbulent period of European politics, and of economic recession, despite encouraging signs of growth potential, the emphasis of many businesses has been placed on cost reduction. There has been, and will be, unrelenting pressure to downsize, to cut costs, to de-layer and to defend market positions.

In many cases this difficult environment has reduced the urge or the drive for quality; quality has been seen as a "low impact" investment or an investment which can be given a lower priority. I'm sure that to many industrialists this statement may seem fairly strange. After all, the emphasis on ISO 9000 and TQM has almost achieved proportions that could lead one to think that a new religion is in the process of being formed. But just how real has this focus been for many companies other than those with high export shares and demanding customers?

The cry for ISO 9000 may often be all we hear - a desperate cry of necessity in order to enter markets through complying with European regulations.

Currently, energies are being directed in many consultative circles at slaughtering the TQM emblem in favour of "Business Process Reengineering" instead of showing greater responsibility by marketing the necessity of and relationships between the sub-elements in both approaches. We get too easily hooked on terms in our eagerness to play with strategic theories divorced from the realities of our own business world and to blame the lack of results on the wrong choice of philosophy or inappropriateness of the acedemic model chosen.

Our company achieved ISO 9001 status in 1992. The procedures, audits and improvement activities that constitute our Quality Management SYSTEM are very important elements of our Total Quality process. We see them collectively as a vital discipline - a way of ensuring 
that we do not let standards slip when times are difficult and business pressures are significant. We do NOT however, regard them as the PRIME driver in our commitment and determination to delight our customers.

At this stage it is appropriate to call to mind the many companies who complain of ISO 9000's so-called total inadequacies. Such statements may often, at further glance, prove to reflect the different companies' own total inadequacies at deploying the standard in the way it was intended, through supplementing it with appropriate methods, tools and strategies for technical and administrative gains. The company's focus on its ISO 9001 quality system is often directed at procedures, papers and product traceability issues, without realizing that these issues, important though they are, will never be effective without an even stronger focus on the company's people, processes and policy deployment.

Many companies are obtaining ISO 9000 registration simply to get on a customer's list of suppliers. They comply with the word of the standard but not with the spirit of Total Quality, and are probably not gaining much benefit from it either. They lack the insight and willingness to be self-analytic and to be severe in their otherwise sincere appraisal of methods employed and results achieved. The fixation is still only on compliance with standards (quality assurance) instead of optimizing the whole company and its results for others.

We are living in a world which, because of good communication and technology, is a much smaller place. Word gets around fast. News of failure, of poor quality, of mismanagement can reverberate around the world and when it happens, customers go elsewhere, because with a shrinking world there is more choice.

But there is an upside. Companies also become recognized as world class, with a stamp synonymous with quality. IBM, Motorola and Digital are international examples. As supplier to all three, Tandberg Data here in Norway recently achieved its "stamp" - the IBM Supplier of the Year Award for Data Storage solutions.

\subsection{SPECIFIC IMPLICATIONS FOR TANDBERG DATA}

For many years this belief - that Quality is THE key factor for global business success - has echoed throughout the Tandberg Data organization, although at troublesome times maybe with varying soundlevels. Our preoccupation with quality started in fact in 1933 with the birth of our forerunner - Tandberg Radiofabrikk, known world-wide for its quality radios and tape recorders.

Tandberg Data defines quality as:

"A product's or a service's total ability to delight the customer through:

- standards

- cost-levels and price conditions

- user requirements, user-reliability and user-friendliness

- defined and latent requirements". 
However, it would of course be futile for Tandberg Data to lull itself into thinking that because it practises TQM, and because it has recognized standards, awards and certification that it will automatically have customers that will remain with us for all eternity. This will depend on our ability to continuously identify, select and adopt the correct strategies and methods for best results at lowest possible use of resources time included.

Nowadays, we have come to realise that total quality has to be integral to our corporate strategy. It is really quite natural that this is so after all, as we all know, customers of electronics continue to demand a continually increasing degree of continuous improvements to the products and services companies provide in partnership with them and to the value for money also provided.

For Tandberg Data, these are now related to PC's, work-stations, terminals, systems for digital storage of data, sound and pictures, as well as LCD peripheral equipment for PC's and the audio-visual market. Global and even national competition in many of these areas is significant. There is an increasing awareness that in this fierce competition, business results related to customer satisfaction, employee satisfaction, environmental and social aspects are important prerequisites to solid financial results, and that the pre-requisites can only be fulfilled through focusing on strategic management, policies, resource deployment issues and process management techniques and principles that are loyal to the concept of a comprehensive, company-wide Total Quality infrastructure.

Tandberg Data began the Total Quality journey in 1988. Even though we were also at that time highly regarded for our innovative thinking regarding the introduction of new technologies, products and processes, it was obvious that our focus need to be more all-embracing for own benefit, besides that of our shareholders and customers. We had always listened carefully to what our customers were telling us in surveys, in consumer groups, in customer contact programmes, through complaints, during product launches, and so on. They pointed out our shortcomings only too clearly. Although our product quality levels more than held their own in the face of comparable competition, two main things were happening:

1. The quality of our competitors was steadily improving.

2. The quality of their services was improving almost equally.

The clarity of our shortcomings was directly proportional to the interest we showed in revealing them ! We needed to bring our house in better order, to structure our approaches, our deployment of methods and our company-wide involvement to deliver more than satisfactory results for our customers, owners and fellow workers - suppliers included.

We began this process in the management team through increasing the knowledge and appreciation of Total Quality as expressed through our important strategic alliances with companies such as IBM, Digital Equipment Corporation and Motorola. Our desire to sustain these relationships was dependent on our ability to involve all parts of the 
organization in a joint, continuous effort to improve quality, productivity, responsiveness and flexibility in internal as well as external

relationships.

First we had to involve all employees and functions in documenting what was expected of them and their services and how these should be performed for optimum results, then we had to provide a set of tools for them to continually improve the handling and results of these services. All workers on all levels had to do two things daily:

1. Perform work tasks according to accepted guidelines and principles.

2. Continually improve their work performances as well as the guide-

lines and principles these are based on.

The first sentence of the European Foundation for Quality Management's policy document reads: "Quality is a key factor for global business success". NOW, my company would go beyond that and say that "Quality is THE key factor for global business success".

\subsection{OUR NEED FOR BENCHMARKING}

What has all this got to do with Benchmarking ? Well, it must be said that adherence to quality system standards, receiving customer quality awards, and numerous company-wide ongoing improvement tasks, impressing though it may seem, quite simply isn't enough ! After all, what is the point of continuously improving a process that shouldn't be there in the first place! We may not know that a process is superficial until we have studied how others receive similar results.

In addition, the company had to continually evaluate - through Benchmarking and Self Assessment - three main things:

1. The relevance of the strategies chosen.

2. The effectiveness of their translation to specific actions at different stages of the value creation process.

3. The actual results obtained for our customers, shareholders,personnel and society.

The more we began to work with these matters, based on knowledge and experience from our large international customers and suppliers, from research institutions at home and abroad, and more recently also from the European Foundation for Quality Management, the more we realized that Benchmarking and Self Assessment of the company's ability to practice TQM principles in its dealings with partners internally as well as externally, was the mechanism by which we could improve our whole organization and all processes in order to increase the value output for everyone; most important of all, to continue to improve the quality beyond that expected of our all customers, with steadily reduced use of resources.

The key to achieving this lay in our ability to recognize, implement and follow through appropriate activities. In short, our ability to do the right things and to do them correctly. To do this we needed to start looking at the way others did things and the way still others meant we ought to do things. 
It was utterly inconceivable for Tandberg Data to divorce Quality from the day to day running of the business. It has to be seen relevant to and infuse the thousands of transactions that occur every day. There has to be a continuous focus on outcomes, a relentless avoidance of bureaucracy, and a visible recognition of actions, not just words. Total Quality must be in the corporate bloodstream.

In Tandberg Data's experience, the investment in Quality, and in Bench-marking \& Self Assessment in particular is mandatory. It not only works, but provides substantial results. It is based on the belief that to continuously improve existing processes is essential but equally inadequate; you have to also look at other organizations' choice of processes to obtain similar results. These OTHERS may be competitors or companies in other industries. For Tandberg Data they also include - at company wide level - the European Foundation for Company Management's Assessment Model.

\subsection{PREPARING OUR CASE FOR BENCHMARKING}

Tandberg Data's first attempt at Benchmarking turned out in fact to be more of a Self Assessrnent activity. The company at this time - early 1993 - had not acquired sufficent knowledge of the terms deployed. We studied opportunities for benchmarking at different levels:

- Strategic (Management's Business Policies),

- Macro (Business Plan Implementation), and

- Micro (Operational at Dept./Functional level).

We looked at the approaches used by PIMS (Profit Impact of Market Strategy) and those of TOPP (Norwegian Productivity Improvement Programme) as well as those of our customers.

As mentioned earlier, we decided first to benchmark our strategies and activities aginst the European Foundation for Quality Management's Assessment Model, and then compare the results obtained through the use of our approaches with those of competitors and other businesses regarded as Best in Class.

We were spurred on by increasing demands for increasing productivity and quality levels, but also by a simple story.

The story came from a japanese company and is now well known. The Ford Motor Company was attempting to reduce costs in their accounts payable department which at the time employed some 400 staff. Through an arduous process they managed to reduce staff numbers down to 300 , then to 200 but could NOT take it below that.

When they looked at Toyota they saw a similar department being run by just 15 staff! Toyota had distributed responsibility and had empowered staff to carry out more tasks at a relatively junior level. Specifically, they had given the receiving clerks the authority to make payments directly. 
Consequently, the person at the back door of the plant was able to sign goods in, had the authority to organize distribution and make decisions like authorizing payments that previously were handled by other staff within the organization. The net result was a more efficient, less costly operation. Benchmarking provided a good example of using empowerment to speed up the decision making process. Quality IS time. Or to state the Spanish philosopher Baltasar Gracian who lived 300 years ago - "The wise do sooner what fools do later".

\subsection{READY, GET SET, GO !}

Returning to Tandberg Data's initial attempt at Benchmarking, I would first like to present to you the process initially adopted which consisted of the following 11 steps:

1. Gain insight into Benchmarking \& Self Assessment

2. Develop Commitment

3. Plan the process

4. Communicate the process

5. Re-evaluate insight into Benchmarking \& Self Assessment

6. Document Situational Report for all areas covered by EFQM Model

7. Compare with main criteria and sub-criteria in EFQM Model

8. Integrate results with findings from TOPP's pre-assessment

9. Interest and involve management teams in recommendations

10. Integrate in Strategic Planning Process for business units

11. Review progress

\subsection{Gain insight into Benchmarking \& Self Assessment}

The following represented our main sources of information for this initial stage during which we focused our attention on learning the purpose and principles of Benchmarking:

- Digital Equipment Corporation's Benchmarking Training Materials (Germany)

- $\quad$ PIMS (Profit Impact of Market Strategy) 1993 Conference in Stockholm.

- Self Assessment Workshops under the auspices of the Norwegian Technology Industry's Productivity Programme (TOPP).

- Experience transfer with our largest customer IBM (Rochester) - the first company to win the prestigous Malcolm Baldrige Quality Award in the United States.

- The Benchmarking concept of Bjelland, Dahl \& Partners entitled "Benchmarking with a capital B".

At this stage we focused particularly on examples of Benchmarking used in different functions, on different organizational levels, in different industries grappling with similar challenges and for different strategic purposes. This was very 
much a self-awareness phase where our minds were opened for the variety of opportunities to exploit Benchmarking for productivity, quality or business improvements.

We focused at this stage more on issues relating to micro, or if you like operational Benchmarking where the logical deliveries from an individual function - be it products or services - as well as our existing challenges, could be compared with functions obtaining good results in other organizations.

We came to the conclusion that our first attempt at benchmarking had to come from one of the following broadly defined areas:

- Issues most critical for customer satisfaction

- Expenditures \& Incomes

- Human Resource Development

- Total Quality Management

- Our largest problem processes

- Choice of Technology

- Shipping

- Supplier Development \& Partnerships

- Main cost components

- Measurements of performance

Many different urgent needs for benchmarking or assessment were identified and at the time the company was undergoing a significant restructuring programme. Our management approaches and human resource deployment were under the loop and we decided therefore to take a fresh look at the company as it was immediately prior to restructuring from another angle. As mentioned previously, this angle was provided by the EFQM's Assessment Model. We had earlier been studied by our major customer who certain aspects of the Malcom Baldrige Model to assess our worthiness as potential volume supplier of streamers to the IBM AS400 series worldwide. Now we wanted to take a COMPREHENSIVE look at the company by focusing on ALL aspects of the EFQM's model. Having decided this, we then had to develop commitment in the management team.

\subsection{Develop Commitment}

Commitment would not have been easy to develop, were it not for the fact that ...

1. we had very demanding but also supportive customers

2. the company had already been accepted as member of the EFQM based on its previous quality achievements

3 . the company was at the time in the final stages of a preassessment activity conducted by the TOPP project.

We began by developing commitment among those contributing by offering local support for the activity. These were the quality managers of each newly formed subsidiary following the 
restructuring process. Though interest for the activity was already present among us, it was not always easy to maintain the level of interest. After all, having restructured the company, the new subsidiaries were anxious to show what they were good for without the interference of corporate staff - and rightly so. However, we were also very conscious of the fact that the information obtained from our benchmarking activity would provide us with invaluable insight into appropriate strengths, weaknesses, threats and opportunities that the individual subsidiaries had. This insight could then be infused into the strategic planning process and appropriate priorities made.

Having obtained commitment among ourselves - the quality professionals - we then embarked on selling the idea to the company's Quality Council, which consisted of the company's directors and quality managers. The Council readily approved the activity, although we did not feel at this stage that we had obtained REAL commitment. The exercise was still seen as something of an acedemic exercise rather than a business necessity. This was due to the fact that we had limited time for presentation and that the task in itself was very comprehensive. But at least we had the go ahead and even support in form of allocated time and priority.

In fact, a direct result of our benchmarking was that we disbandoned our Quality Council and integrated its responsibilities into the normal management meetings. This was done in order to be loyal to the concept of Total Quality Management in our business practises, by dealing with issues cross-functionally as well as empowering and listening to all relevant functions in quality planning matters.

\subsection{Plan the Process}

Our chosen benchmarking activity could now get under way by first planning the process involved. We decided to pursue the following ten steps:

1. Translate the EFQM model into Norwegian.

2. Study the model's main elements.

These were, ranked in order of $\%$ weighting:

- Customer satisfaction (20\%)

- Business results (15\%)

- Processes (14\%)

- Leadership (10\%)

- People Management (9\%)

- Policy \& Strategy (9\%)

- Resources (9\%)

- People satisfaction (9\%)

- Effect on society (6\%)

2. Study the main criteria and sub-criteria of each of the abovementioned elements in the model. 
3. Collect information from reports, meetings, personnel interviews and the TOPP pre-assessment report and relate the information to descriptions of each of the model's elements, main criteria and sub-criteria.

4. Compare (Benchmark) the company against the standards required by EFQM for the different elements and criteria.

5. Document strengths and areas for improvement in each area.

6. Communicate the findings to the Quality Council and subsequently through the management meetings.

7. Feed the information into the Strategic Planning Processes.

8. Review strategic and operative plans to see if they increasingly reflect or take into account EFQM criteria.

9. Identify possible links between results obtained and activities these were based on.

10. Spread information to appropriate process managers for synergy effects.

\subsection{Communicate the process}

At this stage we were concerned with communicating the process beyond that of directors and quality personnel to functions such as finance, personnel, logistics, design and manufacturing. We wanted to inform people of what we were doing and why it was important to make a critical, but structured assessment of what we had prioritized in different areas and how effective the results of these priorities were.

This communication stage was handled informally where we exploited our "open-door" culture to more or less chat about the activity to let people get the feeling that the company's quality drive was not just about fine mathematical measurements such as ppm or sigma, but also very much about how effectively we run our business based on total quality management approaches.

\subsection{Re-evaluate insight into Benchmarking \& Self Assessment}

At this point we took a breather and reviewed our knowledge of benchmarking. It was at this point that we had a discussion about whether or not what we were doing was really benchmarking or maybe self-assessment. The conclusion was that we were adopting a benchmarking approach in order to assess ourselves ! Quite honestly we didn't care too much about issues of nomenclature; we were more keen on working in a disciplined way to obtain a useful tool for improvements, no matter what this discipline was really called. 


\subsection{Document Situational Report for all areas covered by EFQM Model}

Here we took a "global" look at ourselves through the eyes of EFQM viewing each of the boxes or elements in the model. We asked ourselves what our own situation was with regard to each of the following five enablers and four results parameters:

\section{ENABLERS:}

\section{- Leadership}

How the directors and managers inspire and drive Total Quality as the company's fundamental process for continuous improvement.

\section{- Policy \& Strategy}

How the company policy \& strategy reflects the concept of Total Quality and how the principles of Total Quality are used in the determination, deployment, review and improvement of policy and strategy.

- People Management

How the company releases the full potential of its people to improve the business continuously.

- Resources

How the company's resources are effectively deployed in support of policy and strategy.

- Processes

How processes are identified, reviewed and if necessary revised to ensure continuous improvement of the company's business.

- Policy \& Strategy

How the company policy \& strategy reflects the concept of Total Quality and how the principles of Total Quality are used in the determination, deployment, review and improvement of policy and strategy.

\section{RESULTS:}

- Customer Satisfaction

What the perception of our external customers is of the company and of its products and services.

\section{- People Satisfaction}

What our people's feelings are about our company.

- Impact on Society

What the perception of our company is among the community at large. This includes views of the company's approach to quality of life, the environment and to the preservation of global resources.

\section{- Business Results}

What the company is achieving in relation to its planned business performance. The company's degree of continuing success in achieving its financial and non-financial targets and 
objectives, and in satisfying the needs and expectations of everyone with a financial interest in the company.

\subsection{Compare with main criteria and sub-criteria in FFQM Model}

At this stage we looked beyond the five enablers and four results parameters mentioned above to study the more specifically defined demands which these include. To take an example, for People Management the specific demands were:

- Continuous improvement in People Management

- Preservation and development of the people's skills and capabilities through recruitment, training and career progression

- The setting of targets by individuals and teams and the continuous review of performance

- The promotion of everyone's involvement in continuous improvement and the empowermnent of people to take appropriate action.

- The achievement of effective top-down and bottom-up communication.

The other eight elements of the model possessed more or less equally detailed demands to be met.

\subsection{Integrate results with findings from TOPP's pre-assessment.}

The findings from TOPP's (Norwegian Technology Industry's Productivity Program) pre-assessment of Tandberg Data were now studied and related to each of the criteria and sub-criteria in the EFQM Assessment Model. Our own information was then supplemented and modified. It is important to note that modifications were only made to quantitative analyses, NOT to our own qualitative evaluations.

We quickly discovered that many of the observations and recommendations made by TOPP were in line with our own assessment. But in some areas - particularly matters relating to cash-flow, return on invstments, liquidity, etc. we obtained the added advantage of TOPP's more detailed analysis.

Our combined focus - broadly speaking productivity from TOPP and quality from Tandberg Data (if these aspects indeed are separable) enabled us to paint a clearer and more meaningful picture of our total situation. We also had the added advantage of drawing on the expertise from TOPP project personnel from universities and research institutes. These personnel either had the advantage of many years business experience at top level, or the equally important advantage of fresh knowledge of internationally accepted methodologies through their doctorate degree studies at the University of Engineering in Trondheim. 


\subsection{Interest and involve management teams in recommendations}

After integrating and supplementing the findings from TOPP, we now had the total picture as seen by both of us. We could now further structure the findings in terms of strengths and areas for improvement. We were careful not to choose the term weaknesses at this stage (although it was mentioned earlier on in our exercise). We did not want to act as judges, more as facilitators or advisors to management and personnel.

Our final benchmarking report consisted of 22 pages of strengths and areas for improvement. We did not, on purpose, make recommendations in the form of priorities. This was a crossfunctional task for management teams of which we were members on more or less equal terms with the other participants. Our aim at this stage was not to SELL anything but to PRESENT. The picture we presented was to be as clearly identifiable with our own activities, challenges, frustrations and ambitions as it was with the EFQM Assessment Model on which it was based. We were very concerned with avoiding the use of provocative statements but were equally concerned with not being too protective by hiding away sensitive but essentially important observations.

\subsection{Integrate in Strategic Planning Process for business units}

This task was given to two functions within each business unit:
1. The Director
2. The Quality Manager

The Director's task was to use the benchmarking report actively in all relevant stages of the unit's strategic planning process. For this to be effective it was necessary to debate priorities, opportunities, capital restraints, economic opportunities, competitor issues, and so on.

The task of the Quality Manager in each of the business units was to keep the process alive in spite of "other short-term, or even long-term urgencies". This was not an easy task. The electronics business does not exactly enjoy the best profit margins these days and time is not only quality as mentioned earlier, but also money.

This challenge for the Quality Manager or facilitator was probably the most demanding one in the whole process. It called for perseverence and determination sometimes in the face of management signals of quite another kind as immediate pressures were brought to bear either from owners, specific customers, dramatic market fluctuations or our own personnel.

The Quality Manager's task of keeping the process alive will continue to be challenging and increasingly call upon his personal and social attributes, his ability to command authority and respect in additon to possessing the technical insight also necessary for the quality assurance aspect of his job. 


\subsection{Review progress} regularly:

Finally, it is the task of all management teams to review

- plans made

- improvement measures identified and accepted

- results obtained from use of recommendations

- results not obtained through lack of use of recommendations

- the appropriateness of the actual assessment model used

- the process of assessment itself

\subsection{CONCLUSION}

Most examples of benchmarking in industry are based on comparison of quantative data. The data is related to measurements of cost per unit, level of customer satisfaction, return on investments, quality performance, delivery times, time to market, time to customer, etc. Experience, has however shown that concentrating exclusively on QUANTITATIVE analyses, often leads to an incomplete analysis that is worth very little.

Quantitative analyses explain WHY the company has chosen to use specific measurement parameters. They explain differences in performance/quality/customer satisfaction/profitability, etc. between company $A$ and company $B$. This difference does need quantifying and expressing in a way that shows the effect on the different operations involved. However, as a rule, QUALITATIVE analyses ought to come BEFORE QUANTITATIVE analyses because the first is a result of the second, and not the reverse. Hence Tandberg Data's choice of a QUALITATIVE benchmarking of its business situation against the EFQM Model for Asessment. This qualitative appraisal is however based in parts on quantitative comparisons administered by TOPP through their relations with other companies in Norway.

It is Tandberg Data's conclusion that Benchmarking activities ought to focus on first obtaining a clear understanding of the working methodologies used in specific areas targeted for improvement, before diving into the intersting and indeed important measuring of results.

May I conclude by recommending that you take a closer look at the European Foundation for Quality Management's (EFQM) activities, or the similar assessment activities of your own national quality organizations, most of whom have adopted similar models.

May I also take the liberty of recommending that you examine Tandberg Data's products and services - the final test of our companywide and global quality effort to serve the market and our partners with their own stated and implicit requirements. 